\title{
Clinical and diagnostic methods for evaluation of sharp foreign body syndrome in buffaloes
}

\author{
Nasr-Eldin M. Aref ${ }^{1}$ and Mohamed A. H. Abdel-Hakiem ${ }^{2}$
}

1. Department of Animal Medicine, Faculty of Veterinary Medicine, Assiut University, Assiut 71526, Egypt;

2. Department of Animal Surgery, Faculty of Veterinary Medicine, Assiut University, Assiut 71526, Egypt Corresponding author: Nasr-Eldin M. Aref, email: nasreldeen.aref@vet.au.edu.eg

Received: 21-12-2012, Revised: 10-02-2013, Accepted: 11-02-2013, Published online: 15-06-2013

\section{How to cite this article:}

Aref NM and Abdel-Hakiem MAH (2013) Clinical and diagnostic methods for evaluation of sharp foreign body syndrome in buffaloes, Vet World 6(9): 586-591, doi: 10.5455/vetworld.2013.586-591

\begin{abstract}
Aim: The present study was designed to evaluate clinically and under laboratory condition the sharp foreign body syndrome (SFBS) in buffaloes with special emphasis on the diagnostic value of radiography, ultrasonography and blood gases and acidbase balance.

Materials and Methods: 196 buffaloes with a history of anorexia, reduction of milk production and no response to previous medical treatment were included in the present study. These animals were subjected to clinical and radiographical examinations. Positive cases for SFBS were further evaluated by sonography, hemato-biochemical and blood gas and acid base balance analysis.

Results: Out of 196 admitted cases, 49 (25\%) cases were confirmed as SFBS by clinical and radiographical examination. Positive cases were subsequently divided into two main categories (complicated and non complicated) according to radiographical and sonographical findings. SFBS with no complication was diagnosed in 16 cases while 33 cases showed various degrees of complication including reticular adhesion (abdominal and diaphragmatic, $\mathrm{n}=23$ ), diaphragmatic hernia ( $\mathrm{n}$ =6) and traumatic pericarditis $(n=4)$. Leukocytosis, hyperprotenemia and increased activity of AST and ALT were of additional values in the diagnosis of SFBS. A consistent finding of primary metabolic alkalosis was recorded in all cases except one with advanced traumatic pericarditis that showed metabolic acidosis.

Conclusion: While there is no substitution for clinical examination, using of ultrasonography and radiography simultaneously are essential for proper evaluation and differentiation between various sequelae of SFBS in buffaloes. Radiography is an efficient tool for visualization of metallic foreign body while ultrasonography is an excellent device in assessing fibrinous deposits. Hemato-biochemical and blood gases and acid base balance are of additional values in discriminating between various outcomes of SFBS.
\end{abstract}

Keywords: acid-base balance, blood gases, buffaloes, radiography, sharp foreign body syndrome, ultrasonography

\section{Introduction}

Traumatic affections of the bovine forestomach such as sharp foreign body syndrome (SFBS) due to ingestion of sharp foreign bodies are still a matter of concern in different veterinary practices all over the world. Devastating economic losses due to striking reduction in milk and meat production, treatment costs, potential fatalities and fetal losses in affected pregnant animals [1] drive researchers to go deep investigating the different aspects of this syndrome. Both animal and human factors are contributing to development of SFBS. Mode of animal prehension and indiscriminate feeding habits, bad nutritional management, heavy industrialization and human habitations are major predisposing factors for the occurrence of such condition in animal. Various disease outcomes secondary to sharp foreign body syndrome (SFBS) could be developed including localized or diffuse peritonitis, reticular adhesion, diaphragmatic hernia, pericariditis and others $[1,2]$.

This article is an open access article licensed under the terms of the Creative Commons Attribution License (http://creativecommons. org/licenses/by/2.0) which permits unrestricted use, distribution and reproduction in any medium, provided the work is properly cited.
Many studies approached the ingested foreign body syndrome [2-5] in cattle, however little were conducted in buffaloes [5]. Additionally, no detailed description of the complications associated with this condition and further evaluation of ultrasonographical findings and systemic deteriorations associated with SFBS; in particularly blood gas and acid base balance are needed. Differential diagnosis of SFBS is also considered a challenge since several diseases have signs of abdominal pain and ruminal disorders in their course. Additionally, thorough understanding of the systemic outcomes of SFBS is essential for providing optimal pre and postoperative cares of such condition. Against this background, the present study was designed to clinically and laboratory evaluate the different conditions associated with SFBS with special reference to radiography, ultrasonography and blood gases and acid base balance findings.

\section{Materials and Methods}

Animals: A total of 196 buffaloes (Bubalus bubalis) were admitted to the Veterinary Teaching Hospital (VTH) at Assiut University- Egypt with a history of anorexia and reduction of milk production from 
September 2011 to January 2012. A past history of receiving of various medical treatments with no response was also reported. Additionally, 6 healthy animals were included in this study as a control. A definite diagnosis of SFBS was reached in 49 cases after careful clinical and radiographical examinations. The affected buffaloes were classified as following:

\begin{tabular}{llcc}
\hline Group & Condition & $\begin{array}{c}\text { Number } \\
\text { Incidence } \\
\text { (\%) }\end{array}$ \\
\hline 1 & Foreign bodies with no complication & 16 & 8.1 \\
2 & Reticular adhesion with abdominal floor & 15 & 7.65 \\
3 & Reticular adhesion with diaphragm & 8 & 4 \\
4 & Diaphragmatic hernia & 6 & 3.06 \\
5 & Pericarditis & 4 & 2.04 \\
& Total & 49 & 25 \\
\hline
\end{tabular}

Clinical assessment: All animals were subjected to thorough clinical examination according to the method of Jackson and Cockcroft [6]. Specific clinical chart was designed and data concerning sex, pregnancy parturition, appetite, milk yield, body condition score, general attitude, pain expression (grunting, tearing, tongue protrusion), eye appearance (conjunctival mucous membranes and sclera blood vessels), body temperature, heart sound and ruminal movement were recorded.

Radiographical examination: The cranial abdominal region and caudal thorax were examined radiographically according to Siegrist and Geissbühler [7] using fixed ceiling X-ray apparatus $(40-60 \mathrm{Kv}$ and $45-$ $55 \mathrm{~mA} / \mathrm{s}$ ). The following criteria were recorded upon radiographical examination: nature and location of foreign body (reticular, diaphragmatic, pericardial position), status of diaphragm (intact versus broken) and visualization of the cardiac area (good versus bad line of demarcation).

Ultrasonographical examination: The area over the heart and reticulum of the left and right sides of the thorax $\left(3^{\text {rd }}-7^{\text {th }}\right.$ intercostal space $)$ up to the level of elbow was examined using $3.5 \mathrm{MHz}$ convex transducer (Veterinary Ultrasound Scanner System -Aqulla Pro.Vet., Maastricht, Netherlands). The reticulum and surrounding tissues were examined as described by Braun and Goetz [8]. The pleura and pulmonary surface were examined as described by Braun et al. [9]. The heart was examined as described by Braun [10].

Laparo-rumenotomy: Exploratory rumenotomy was performed according to Ducharme and Fubini [11].

Blood sampling: Whole blood and serum samples were collected and all precautions of sample collections and preparation for accurate evaluation of hematobiochemical and blood gases and acid - base balance indices were taken into consideration according to Kanekeo, et al., [12].

Blood Gases and acid-base balance analysis: Blood gases and acid-base balance parameters including blood $\mathrm{pH}, \mathrm{PCO}_{2}(\mathrm{mmHg}), \mathrm{PO}_{2}(\mathrm{mmHg}), \mathrm{HCO}_{3}$ $(\mathrm{mmol} / \mathrm{l}), \mathrm{tCO}_{2}(\mathrm{mmol} / \mathrm{l})$ and $\mathrm{BE}(\mathrm{mmol} / \mathrm{l})$ were measured using ABL5 Blood Gas Analyser (Radiometer,
Denmark). The machine was calibrated and subjected to test of quality control before assay.

Complete blood count (СBC) assessment: A fully automated blood cell counter machine, Medonic CA620 Vet hematology analyzer-Sweden, was used to determine total red blood cell count (TRBCs$\left.\times 10^{6} / \mathrm{mm}^{3}\right)$, hemoglobin concentration $(\mathrm{Hb}-\mathrm{g} / \mathrm{dl})$, packed cell volume (PCV\%), total and differential leuckocytic counts (TWBSc- and DLC $\times 10^{3} / \mathrm{mm}^{3}$ ).

Biochemical assays: Spectrophotometric method using Phillips Pye Unicam spectrophotometer (U.V. Visible Mod. 800) was adopted to determine serum concentrations of total protein (Biuret) and liver enzymes (ALT and AST). All kits and reagents were obtained from Spectrum Reagents (Egyptian Company for Biotechnology, Cairo, Egypt).

Statistical analysis: Data were analyzed using the packaged SPSS program for windows version 10.0.1 (SPSS Inc., Chicago, IL). All data were presented as mean \pm standard error (SE). Differences between groups were determined by LSD Post hoc test. Significance level was set at $\mathrm{P} \leq 0.05$.

\section{Results and Discussion}

Incidence and clinical findings: SFBS is one of the most commonly occurring diseases of the digestive tract of large ruminants. It was recorded in 49 cases (25\%) of examined buffaloes. Age of affected animals was ranged from 4-9 years old. Out of the 49 animals, 21 were pregnant $(42.85 \%), 16$ were recently calved (32.6\%), 7 were non-pregnant (14.28\%) and 5 cases were male $(10.2 \%)$.

All cases examined in the present study were admitted to our clinic with one case history: off food, weight loss and decrease in milk production. Affected animals with SFBS had common clinical signs: congested conjunctival mucous membrane and engorgement of scleral blood vessels while pain expression (tearing, opening of mouth and protrusion of tongue) was evident in complicated cases (group 25). The intensity of pain expression was augmented by conducting deep percussion on xiphisternum. The body condition score of affected animals was varying from thin to well-conditioned. Affected animals showed varying degree of depression except for non complicated cases (group 1). The rectal temperature varied from 38.5 to $39.5^{\circ} \mathrm{C}$. Tachycardia was consistent finding in animals suffered from traumatic pericarditis (90-100 beats/minute) while bradycardia and barely audible heart sounds were noticed in animals with diaphragmatic hernia (50-60 beats/minute). Auscultation of the rumen revealed reduction to complete cessation of ruminal movement in all cases. L-shape (papple slipped) abdomen was noticed in one case (Figure-1). Brisket edema was not markedly evident while distension/pulsation of the jugular vein was obvious in cases of traumatic pericarditis in affected buffaloes 


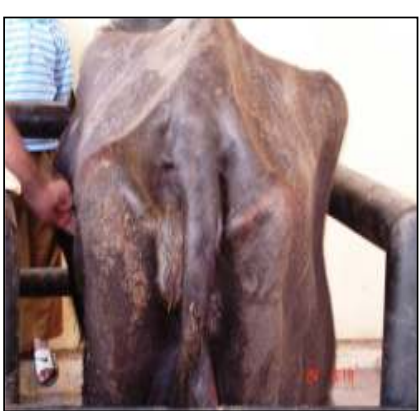

Figure-1. L-shape abdomen in 8year-old buffalo. The case was diagnosed clinically as "vagus indigestion" and confirmed surgically as "reticular adhesion" at the ventral abdominal wall.

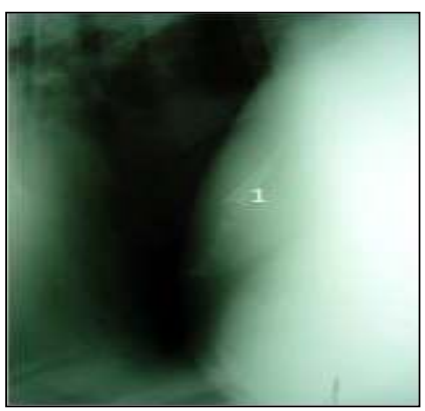

Figure-5. Lateral plain radiography of the cranial abdominal and caudal thoracic regions in 5-yearold buffalo showing radio-opaque metallic foreign bodies ( 1 . nails) at the diaphragmatic surface of the reticulum.

(Figure-2). Compared to cattle, it was observed that pain expression especially tearing and engorgement of scleral blood vessels were remarkably obvious in buffaloes while brisket edema was less prominent feature. These observations were in agreement with Misk and Semieka [13]. Grunder [14] stated that in the presence of a patent foreign body-creating tract, the pericardial fluid drains into the reticulum and edema may not be obvious in such a case. This may be common in buffalo than cattle. Finally, we strongly think that clinical examination of suspected cases of SFBS represents the basic step for diagnosis; however additional diagnostic aids are also substantial.

Radiographical findings: Application of radiography in the present study provided remarkable information regarding visualization of metal foreign body and accurate information about their type and position in and outside the reticulum $[7,15]$. Left lateral recumbent plain radiographs of the cranial abdominal and caudal thoracic regions have been performed in clinically healthy (Figure-3) and affected buffaloes (Figures 412). Affected animals showed different radio-opaque metallic foreign bodies (needles, hair-pins and wires)
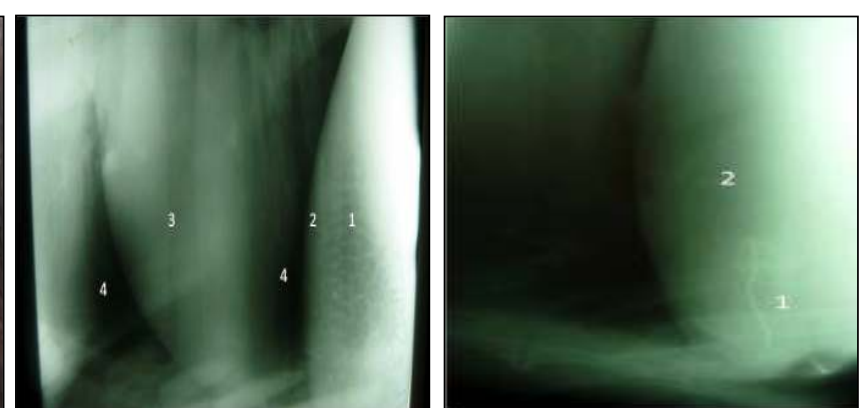

Figure-3. Lateral plain radiography Figure-4. Lateral plain radiography of the cranial abdominal and of the cranial abdominal and caudal thoracic regions in 6-year- caudal thoracic regions in 7-yearold buffalo showing normal $x$-ray old buffalo showing radio-opaque findings (1. Honey comb cells of metallic foreign body (1. long the reticulum 2. line of diaphragm, wire) within the reticulum (2). 3. heart and 4. lung).
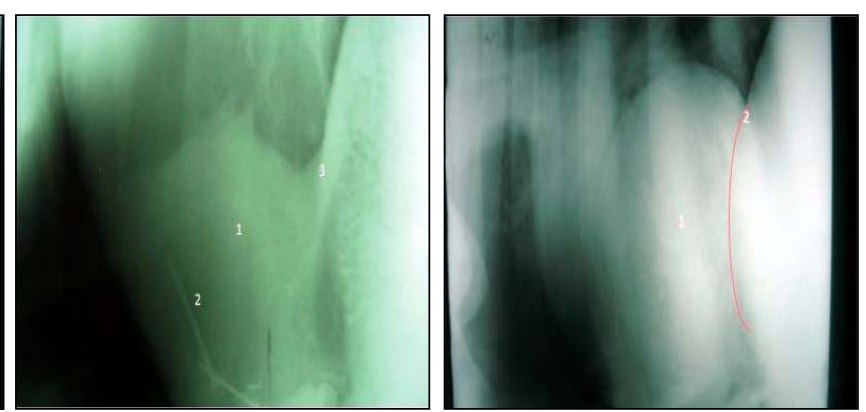

Figure-7. Lateral plain radiography Figure-8. Lateral plain radiography Figure-6. Lateral plain radiography Figure-7. Lateral plain radiography Figure-8. Lateral plain radiography
of the cranial abdominal and of the cranial abdominal and of the cranial abdominal and caudal thoracic regions in 9-year- caudal thoracic regions in 4-year- caudal thoracic regions in 6-yeartallic foreign bing radio-opaque old buffalo showing circumscribed old buffalo showing circumscribed (1) containing radio reticulum (1) within the thorax (2) dense metallic foreign body (2) and overlying the caudal border of diaphragm and the apex of the with discontinuation of the (2). The case was diagnosed diaphragm (3). The case was clinically as SFBS and confirmed diagnosed clinically as SFBS and radiographically as diaphragmatic confirmed radiographically as hernia.

diaphragmatic hernia

within the reticulum. These sharp metallic foreign bodies have different position with various sequelae. Some foreign bodies penetrated the ventral portion of the reticulum causing traumatic reticuloperitonitis (TRP) with abdomino-reticular adhesion (Figure-4) while others were found in close contact with the diaphragmtic surface of the reticulum (Figure 5, 6) causing TRP with phrenicoreticular adhesion. It was observed that this adhesion was reflected clinically on the affected animals with signs of vagus indigestion.

Diaphramatic hernia (Figure 7,8) was visualized on the radiograph in three cases as a circumscribed swelling of soft tissue density (reticulum) within the thorax and overlying the caudal border of the heart with discontinuation of the diaphragm. Bradycardia and barely audible heart sounds in this group were attributed to displacement of the heart away from the chest wall due to reticular herniation.

Another three cases were diagnosed as traumatic pericariditis. The radiograph showed needle passes through the diaphragm in two cases (Figure-9) while one case has lost its radiographic details on the chest due to massive pericardial exudation (Figure-10).

Non complicated cases (16/49) showed different 

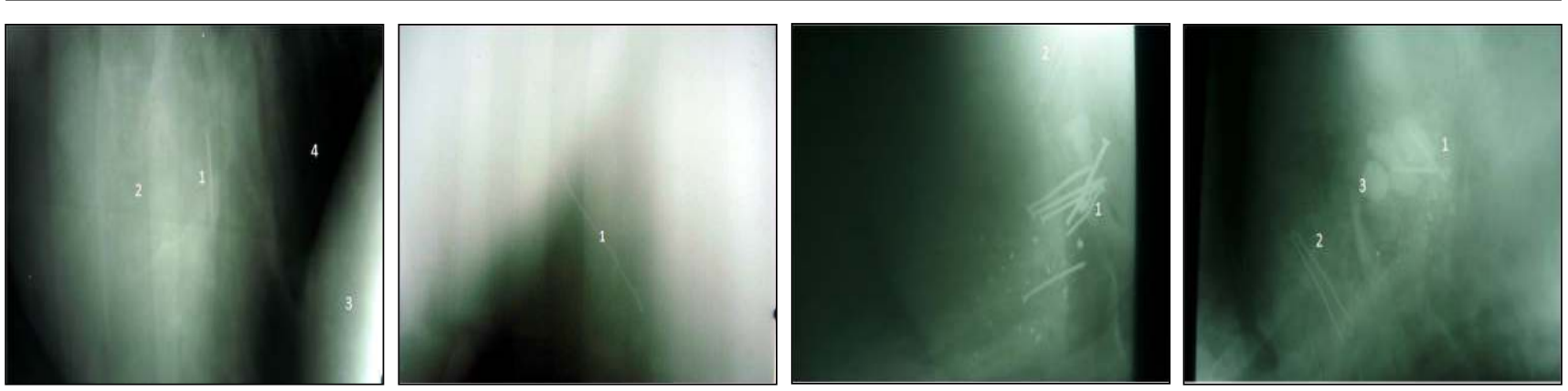

Figure-9. Lateral plain radiography Figure-10. Lateral plain radiography Figure-11. Lateral plain radiography Figure-12. Lateral plain radiography of the cranial abdominal and of the cranial abdominal and of the cranial abdominal region in of the cranial abdominal region in caudal thoracic regions in 5-year- caudal thoracic regions in 6-year- 5-year-old buffalo showing large 7-year-old buffalo showing old buffalo showing radio-opaque old buffalo showing radio-opaque number of radio-opaque metallic different types of radio-opaque heart (2), reticulum (3) and lung the pericardial sac with exudates. (4). The case was diagnosed as The case was diagnosed as traumatic pericarditis. traumatic pericarditis.

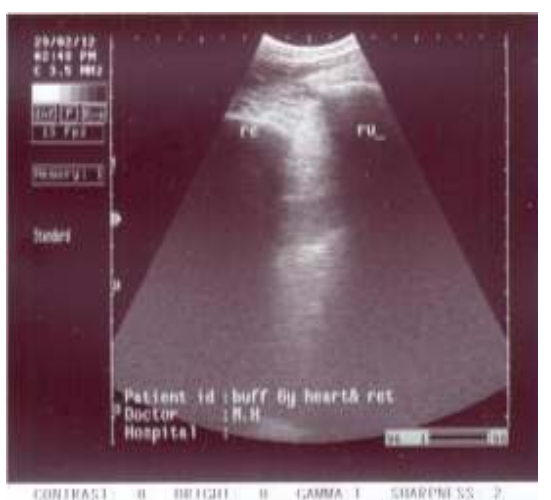

Figure-13. Ultrasonogram at the left parasternal region of 6-year-old healthy buffalo showing the reticulum (re) and cranial sac of the rumen (ru).

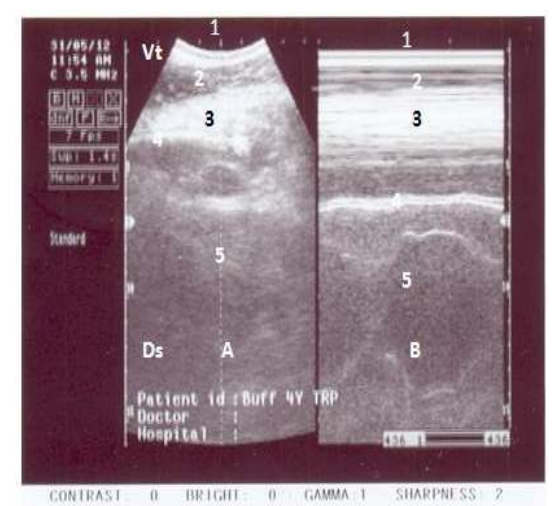

Figure-14. Ultrasonogram using the $B$ mode (A) and BM mode (B) on 4-year-old buffalo suffered from TRP. The transducer was applied at the left parasternal region showing hyperechoic deposits between the abdominal and reticulum wall suggestive fibrin deposit and adhesion (3). Skin (1) abdominal wall (2), adhesion (3), reticular wall (4) and reticulum (5). hair-pin (2) and non metallic foreign bodies- rocks (3) within the reticulum

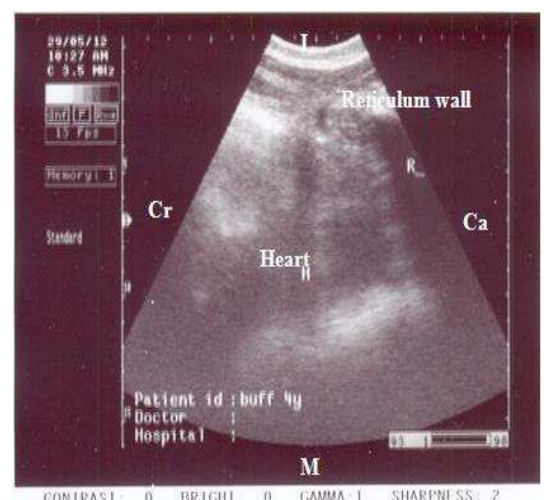

Figure-15. Lateral view of ultrasonography in 4-year-old buffalo: Application of transducer on $3^{\text {rd }}$ and $4^{\text {th }}$ ICS showing have moon shape of reticulum inside the thorax. The case was diagnosed and confirmed as diaphragmatic hernia. non-penetrated metallic foreign bodies (Figure 11, 12).

Ultrasonographical findings: Conducting sonographic examination provided excellent data about the presence of fibrinous deposits between the reticulum and abdominal wall that could not be visualized by radiography. Ultrasonography of the left and right parasternal region in clinically healthy (Figure-13) and affected buffaloes (Figure 14,15) was performed. Sonogram of the affected animals showed deposits of various echogenicities between reticulum and abdominal wall (Figure-14). Diaphragmatic hernia was diagnosed by placing the transducer at 3rd -4th ICS of left and right sides of the thorax (Figure-15). The presence of the half moon shape reticulum at this position strongly suggesting diaphragmatic hernia and this was in agreement with the finding of Abouelnasr et al., [4]. The major advantage of ultrasonography overcomes not only the problem of locating the lesion but also its size and extent however, it failed to identify any metallic objects. This was in agreement with earlier findings reported by Braun, et al., [16]. Thus, it could be strongly suggested that application of radiography and ultrasonography simultaneously afford an excellent approach to precisely evaluate the different conditions associated with SFBS.

Laparo-rumenotomy: Exploratory rumenotomy was performed in $68.75 \%(11 / 16)$ cases in group $1,100 \%$ in group 2 and 3 while the operation was not performed in group 4 and 5. Variable size and number of metallic foreign bodies were removed from the reticulum. Adhesions were clearly noticed in group 2 and 3 . These animals expressed weak and interrupted reticular contractions. Ruminal content was not fully macerated (impacted rumen). Three cases of abdominal adhesion (group 2) showed atonized reticul-omasal orifice (RO). Atonized RO in these animals could be attributed to damaged vagus nerve and development of vagus indigestion. Highly impacted rumen was observed in two cases while one case showed undigested food materials in the ventral sac of the rumen with large quantities of fluid on the top (dorsal sac of the rumen).

Blood gases and acid-base balance findings: Data of venous blood gases and acid base balance of various groups are listed in Table 1. Statistical analysis of these data revealed significant differences between each group compared to control group. $98 \%$ of cases (48/49) 
Table-1. Mean values $( \pm S E)$ of blood gases and acid-base status in control and different conditions of SFBS in buffaloes

\begin{tabular}{|c|c|c|c|c|c|c|}
\hline \multirow[t]{2}{*}{ Parameter } & \multirow[t]{2}{*}{ Control $(n=6)$} & \multirow{2}{*}{$\begin{array}{l}\text { Not Complicated } \\
\text { Floating FB } \\
(\mathrm{n}=16)\end{array}$} & \multicolumn{4}{|c|}{ Complicated } \\
\hline & & & $\begin{array}{l}\text { Adhesion with } \\
\text { abdominal floor } \\
\text { ( } n=15)\end{array}$ & $\begin{array}{l}\text { Adhesion with } \\
\text { diaphragm } \\
(\mathrm{n}=8)\end{array}$ & $\begin{array}{l}\text { Diaphragmatic } \\
\text { hernia } \\
(n=6)\end{array}$ & $\begin{array}{l}\text { Pericarditis* } \\
(\mathrm{n}=\mathbf{3})\end{array}$ \\
\hline $\begin{array}{l}\mathrm{pH} \\
\mathrm{PCO}_{2} \\
\mathrm{PO}_{2}\end{array}$ & $\begin{array}{l}7.38 \pm .007^{\mathrm{a}} \\
42.16 \pm 0.98 \\
37.16 \pm 0.60\end{array}$ & $\begin{array}{l}7.45 \pm 0.01^{b} \\
44.37 \pm 1.78 \\
39.71 \pm 3.44\end{array}$ & $\begin{array}{l}7.46 \pm 0.01^{b} \\
43.75 \pm 0.62 \\
35.50 \pm 4.33\end{array}$ & $\begin{array}{l}7.49 \pm 0.01^{b} \\
37 \pm 2.08 \\
36.67 \pm 5.36\end{array}$ & $\begin{array}{l}7.48 \pm 0.06^{b} \\
34.0 \pm 1.0 \\
41.07 \pm 7.36\end{array}$ & $\begin{array}{l}7.45 \pm 0.02^{b} \\
42.33 \pm 1.45 \\
44.33 \pm 4.63\end{array}$ \\
\hline $\mathrm{HCO}_{3}$ & $26.33 \pm 0.49^{a}$ & $29.62 \pm 0.96^{b}$ & $30.25 \pm 0.94^{b}$ & $27.67 \pm 1.45^{b}$ & $27.0 \pm 3.05^{b}$ & $29 \pm 0.57^{b}$ \\
\hline $\mathrm{tCO}_{2}$ & $28.83 \pm 0.74^{a}$ & $31.0 \pm 0.88^{b}$ & $32 \pm 1.08^{b}$ & $28.67 \pm 1.45^{b}$ & $28.67 \pm 1.45^{b}$ & $30 \pm 0.58^{b}$ \\
\hline $\mathrm{BE}$ & $1.82 \pm 0.30^{\mathrm{a}}$ & $5.50 \pm 0.90^{b}$ & $6.26 \pm 0.94^{b}$ & $5.0 \pm 1.15^{b}$ & $4.0 \pm 3.0^{b}$ & $5.0 \pm 0.92^{b}$ \\
\hline
\end{tabular}

* One case of pericarditis that showed metabolic acidosis was not included

Different superscripts in the same row indicate a significant difference at $P<0.05$

Table-2. Mean values $( \pm S E$ ) of haematological and biochemical indices in control, complicated and non complicated groups of SFBS in buffaloes

\begin{tabular}{llll}
\hline Parameters & Control & Non complicated & Complicated \\
\hline TRBCs $\left(\times 10^{6}\right)$ & $5.28 \pm 0.72^{\mathrm{a}}$ & $5.91 \pm 0.22^{\mathrm{a}}$ & $6.67 \pm 0.59^{\mathrm{a}}$ \\
$\mathrm{Hb}(\mathrm{g} / \mathrm{dl})$ & $11.74 \pm 1.52^{\mathrm{a}}$ & $12.74 \pm 0.52^{\mathrm{a}}$ & $11.65 \pm 0.89^{\mathrm{a}}$ \\
PCV $(\%)$ & $28.56 \pm 3.79^{\mathrm{a}}$ & $29.33 \pm 2.23^{\mathrm{a}}$ & $33.12 \pm 3.46^{\mathrm{a}}$ \\
TWBCs $\left(\times 10^{3}\right)$ & $5.17 \pm 0.80^{\mathrm{a}}$ & $6.45 \pm 1.8^{\mathrm{a}}$ & $10.28 \pm 1.36^{\mathrm{b}}$ \\
Granulocyte $\left(\times 10^{3}\right)$ & $0.20 \pm 0.04^{\mathrm{a}}$ & $1.31 \pm 0.04^{\mathrm{b}}$ & $4.51 \pm 1.20^{\mathrm{b}}$ \\
Lymphocytes $\left(\times 10^{3}\right)$ & $4.42 \pm 0.83^{\mathrm{a}}$ & $4.45 \pm 0.34^{\mathrm{a}}$ & $4.07 \pm 0.82$ \\
MID $\left(\times 10^{3}\right)$ & $0.50 \pm 0.08^{\mathrm{a}}$ & $0.50 \pm 0.08^{\mathrm{a}}$ & $1.74 \pm 0.37^{\mathrm{b}}$ \\
Serum TP $(\mathrm{g} / \mathrm{dl})$ & $6.30 \pm 0.92^{\mathrm{a}}$ & $6.89 \pm 1.3$ & $8.53 \pm 1.19^{\mathrm{b}}$ \\
Serum AST $(\mathrm{iu} / \mathrm{l})$ & $80.19 \pm 2.30^{\mathrm{a}}$ & $77.30 \pm 3.29$ & $173.16 \pm 16.50^{\mathrm{b}}$ \\
Serum ALT (iu/l) & $35.67 \pm 2.23^{\mathrm{a}}$ & $37.89 \pm 1.28$ & $62.12 \pm 3.59^{\mathrm{b}}$ \\
\hline
\end{tabular}

Different superscripts in the same row indicate a significant difference at $\mathrm{P}<0.05$

showed a consistent finding of primary metabolic alkalosis. A significant rise $(P<0.05)$ in their blood $\mathrm{pH}$ value compared to control one was detected. The laboratory indices of metabolic side of blood gases and acid base balance of these cases including base excess (BE), bicarbonate $\left(\mathrm{HCO}_{3}\right)$ and total carbon dioxide $\left(\mathrm{tCO}_{2}\right)$ concentrations, showed significant increase $(P<0.05)$ with no compensation while cases with diaphragmatic adhesion or hernia showed reduction in their $\mathrm{PCO}_{2}$ value. This alteration in the blood gases and acid base balance in favor of alkalosis is probably due to anorexia and ruminal hypomotility associated with these conditions. It is well known that rumen cannot maintain normal plasma/rumen electrolytes gradients and ruminal chloride ions increased and sequestrated in cases of severe ruminal hypomotility [12]. Loss of chloride ions inside the rumen is usually associated with metabolic alkalosis. Surprisingly, one case with advanced pericarditis showed decrease in blood $\mathrm{pH}$, $\mathrm{BE}$ and $\mathrm{HCO}_{3}$ values suggesting a case of primary metabolic acidosis. This might be attributed to development of toxemia and congestive heart failure. Endotoxaemia mostly likely developed in advanced pericarditis. Additionally, reduction in cardiac output leads to decrease in tissue perfusion resulting in acidosis [12].

Haematological and biochemical findings: A significant increase in total leukocytic count was noticed in complicated cases $(10.28 \pm 1.36)$ compared to uncomplicated $(6.45 \pm 1.8)$ and control $(5.17 \pm 0.80)$ ones. Highly significant increase in granulocyte was observed in complicated cases as compared to control group.
Erythrogram showed varied pattern, however cases with poor body condition score showed reduction in RBCs count to the lower reference range. Serum total protein showed significant increase in complicated case (adhesion cases) compared to control one. Data of hematological and biochemical findings are presented in Table-2.

Leukocytosis with granulocytosis in complicated cases might suggest but not confirm ingestion of sharp body. These findings were agreed with öcal, et al., [17] suggesting an underlying inflammatory condition. Hyperproteniemia and increase activities of AST and ALT are consistent findings in complicate cases in this study. This is in agreement with previous studies [18, 19] and supports the notation of presence of tissue destruction and an underlying inflammatory condition. Leukocytosis with granulocytosis, increased concentration of serum total protein and enzymatic activities of liver enzymes are often a reflection of cellular destruction and inflammatory response to the ingested foreign bodies [12].

\section{Conclusion}

SFBS is a common GIT problem in buffaloes and thorough medical evaluation is needed before initiating surgical operation. Clinical signs and hematological findings are of great values; however additional diagnostic aids are essential. Radiography and ultrasongraphy are complementary and important tools for making proper diagnostic decision. Radiography detects metallic foreign bodies and their location while adhesion and effusion in the thorax, pericardium and abdomen can be detected and characterized by sonography. While 
the data of blood gas and acid base balance came within our expectation (primary metabolic alkalosis), one case with advanced pericarditis had metabolic acidosis. This might draw attention to the potential link between acidosis and the presence of severe pericarditis in SFBS.

\section{Authors' contributions}

Both author have formulated the research plan and conducted the study equally. NMA wrote the manuscript. Both authors discussed the results and revised the manuscript. Both authors approved the final manuscript.

\section{Acknowledgements}

The authors are grateful to the Director of Veterinary Teaching Hospital at Assiut University for support during this study.

\section{Competing interests}

The Authors declare that they have no competing interests.

\section{References}

1. Radostits, O.M., Gay, C.C., Hinchcliff, K.W. and Constable, P.D. (2007) Diseases of the alimentary tract. In: Radostits O.M., Gay C.C., Hinchcliff K.W., and Constable P.D. (eds.): Veterinary Medicine. A Textbook of the Diseases of Cattle, Horses, Sheep, Pigs and Goats. 10th ed. Saunders Elsevier, Philadelphia. Pp 189-382.

2. Roth, L., King, J.M. (1991) Traumatic reticulitis in cattle: a review of 60 fatal cases. J. Vet. Diagn. Invest. 3: 52-54.

3. Floeck, M. and Baumgartner W. (2001) Ultrasonographic diagnosis of traumatic reticuloperitonitis and pericarditis in cattle (in German). Wiener Tieraerztliche Monatsschrift.; 12: Pp 347-354.

4. Abouelnasr, K.S., Mosbah, E., Karrouf, G. I. and Zaghloul, A.E. (2012) Comparative ultrasonographic findings of traumatic reticulitis, perireticular abscess and diaphragmatic hernia in buffalo (Bubalus Bubalis). J. Am. Sci. 12:590-595.

5. Abdelaal, A.M., Floeck, M., El Maghawry, S. and Baumgartner W. (2009) Clinical and ultrasonographic differences between cattle and buffaloes with various sequelae of traumatic reticuloperitonitis. Veterinarni Medicina. 54: Pp 399-406.
6. Jackson, P. and Cockcroft, P. (2008) Clinical examination offarm animals. 1st edition, John Wiley \& Sons, Pp7-216.

7. Siegrist A, and Geissbühler U. (2011) Radiological examination of cattle, Tierarztl Prax Ausg Grosstiere Nutztiere. 39: Pp 331-40.

8. Braun U. and Goetz M. (1994) Ultrasonography of the reticulum in cows. Am. J. Vet. Res. 55: Pp 325-332.

9. Braun U., Sicher, D. and Pusterla N. (1996) Ultrasonography of the lungs, pleura, and mediastinum in healthy cows. Am J Vet Res. 57: Pp 432-438.

10. Braun, U. (2009) Traumatic pericarditis in cattle: Clinical, radiographic and ultrasonographic findings. The Veterinary Journal. 182: Pp 176-186.

11. Ducharme, N.G. and Fubini S.L. (2004) Surgery of the ruminant forestomach compartments. In: Fubini SL, Ducharmi NG. (eds) Farm animal surgery. Elsevier science, Saunders, USA. Pp184-194.

12. Kanekeo, J.J.; Harvey, J.W. and Bruss, M. (2008) Clinical biochemistry of domestic animals. 6th ed., Academic Press, Academic Press, Elsevier Inc., San Diego, California, USA. Pp 529-559.

13. Misk, N.A. and Semieka, M. A. (2001) The radiographic appearance of reticular diaphragmatic herniation and traumatic pericarditis in buffaloes and cattle. Veterinary Radiology and Ultrasound. 42: 426-430.

14. Grunder, H.D. (2002) Krankheiten des Herzens und des Herzbeutels. In: Dirksen, G., GrÜnder, H.D., Stöber, M. (Eds.), Innere Medizin und Chirurgie des Rindes, fourth ed. Parey Buchverlag, Berlin, pp. 159-181.

15. Braun, U., Fluckiger, M. and Nageli, F. (1993) Radiography as an aid in the diagnosis of traumatic reticulo-peritonitis in cattle. Vet. Rec. 132: Pp 103-109.

16. Braun, U., Pusteria, N. and Auliker, H. (1998) Ultrasonographic findings in three cows with peritonitis in the left flank. Vet. Rec. 142: Pp 338-340.

17. Öcal, N., Gökce, G., GÜcÜs, A.I., Uzlu, E., Yağet, B.B. and Ural, K. (2008) Pica as a predisposing factor for traumatic reticulopertonitis in dairy cattle: Serum mineral concentrations and hematological finding. J. Anim. Vet. Sci. 7: Pp 651-656.

18. Dubensky, R.A. and White, M.E. (2008) The sensitivity, specificity and predictive value of total plasma protein in the diagnosis of traumatic reticuloperitonitis. Can. J. Comp. Med. 1983, 7: 241-244.

19. Saleh, M.A., Rateb, H.Z. and Misk, N.A. (2008) Comparison of blood serum proteins in water buffaloes with traumatic reticuloperitonitis and sequelae. Res. Vet. Sci. 85: Pp 208213. 